\title{
DESIGN \& EXPERIÊNCIA SENSORIAL: ESTUDO DE CASO SOBRE UM SUPERMERCADO EM MANAUS
}

\section{DESIGN \& SENSORY EXPERIENCE: CASE STUDY ON A SUPERMARKET IN MANAUS}

\author{
Beatriz Loris ${ }^{1}$, Bach. \\ beatriz.fonseca@super.ufam.edu.br \\ Yamille Santos ${ }^{1}$, Bach. \\ yamille.barbosa@super.ufam.edu.br \\ Karla Mazarelo ${ }^{1}$, Dra. \\ karlamazarelo@ufam.edu.br
}

\footnotetext{
${ }^{1}$ Departamento de Design e Expressão Gráfica, Universidade Federal do Amazonas - UFAM, Manaus, Brasil
}

design, experiência sensorial, percepção e sentido

Em meio a um cenário corporativo cada vez mais competitivo, o design sensorial utiliza-se de estratégias que atendem empresas que buscam novas tendências comerciais, para cativar e consolidar clientes, além de obter destaque no mercado. Desse modo, o artigo evidencia a relevância da experiência sensorial, por meio do estudo de caso sobre um supermercado em Manaus que proporciona a estimulação multissensorial em seu estabelecimento. Para atingir este fim, fez-se um estudo com abordagem quantitativa e qualitativa, com objetivos de caráter exploratório e descritivo, fundamentados em pesquisas bibliográficas, documentais e de campo, consulta de opinião através de questionário online, aplicação da técnica focus group e a utilização do método projetual de Bruce Archer. Os resultados identificam os aspectos sensoriais relevantes no ambiente da empresa, apontando os pontos positivos e negativos do objeto de estudo. Dessa forma, a contribuição deste estudo, destina-se a pontuar a importância do design sensorial em dedicar-se estrategicamente para produzir experiências positivas e proporcionar memórias afetivas aos usuários.

\section{design; sensory experience; perception and senses}

In the midst of an increasingly competitive corporate scenario, the sensory design uses strategies that serve companies seeking new commercial trends, to captivate and consolidate customers, in addition to gaining prominence in the market. Thus, the article highlights the relevance of the sensory experience, through the case study of a supermarket in Manaus that provides multisensory stimulation in its establishment. To achieve this end, a study was carried out with a quantitative and qualitative approach, with exploratory and descriptive objectives, based on bibliographic, documentary and field research, opinion consultation through an online questionnaire, application of the focus group technique and the use of Bruce Archer's design method. The results identify the relevant sensory aspects in the company's environment, pointing out the positive and negative points of the object of study. Thus, the contribution of this study is intended to highlight the importance of sensory design in strategically dedicating itself to producing positive experiences and providing effective memories to users. 


\section{Introdução}

Os avanços das tecnologias juntamente as mídias sociais advindas do processo de globalização, afetaram o modo como os clientes interagem com as empresas, com melhorias no acesso de informações, a população tem maior autonomia para saber o que esperar de uma marca. Segundo Guimarães (2011), observa-se que o público não é mais um mero espectador, desta forma as pessoas procuram conhecer novas tendências comerciais, assim como expressar suas opiniões e exercer influência sobre outros compradores. Diante dessa nova perspectiva, conquistar e fidelizar o público, tornou-se um desafio para estabelecimentos de vários segmentos, pois diante a um cenário competitivo e saturado onde possui inúmeras opções de oferta de produtos e serviços, impõe-se a necessidade de pesquisar novas estratégias para aprimorar a experiência do usuário e ganhar espaço na preferência do público. Nesse sentido, o design possui diversas áreas que podem ser exploradas, conforme a necessidade, pode-se encontrar métodos e ferramentas, com o propósito de adequar às crescentes exigências dos consumidores, como também diferenciar a identidade corporativa e destacar sua presença no mercado.

Ao buscar contornar esta situação em que o mercado se apresenta saturado, surge como alternativa o design sensorial, o qual busca estimular os sentidos do público ao interagir com ambiente ou produto, com a finalidade de os envolver emocionalmente. Os autores Turpault, Tannen e Welsh (2013), consideram o design sensorial como uma ferramenta que permite ir além dos aspectos visuais, utilizando elementos sutis, para criar ligações subconscientes e profundas com a marca, essa tendência promove oportunidades memoráveis e estimulantes ao usuário. Benites (2016), descreve que os consumidores são atraídos pela experiência oferecida pelo local, a aquisição do produto de determinada loja não é tão importante quanto à vivência pela qual é envolvido. Desta maneira, destaca-se a relevância de projetar visando a experiência do usuário, pois contribui para agregar valor à marca, bem como atrair e fidelizar os clientes. Segundo Lindstrom (2011), isso acontece, pois, os estímulos sensoriais se incorporam na memória do consumidor a longo prazo, tornando-se assim parte do processo decisório. Portanto, nota-se uma interação maior dos clientes com estabelecimentos que oferecem um vínculo emocional.

Mediante o exposto, a presente pesquisa surge de um vasto interesse pelo tema design e experiência sensorial, buscando identificar como os estímulos multissensoriais são trabalhados para desenvolver vínculos emocionais entre consumidores e a marca. Nesse sentido, foi realizado um estudo de caso sobre um supermercado, localizado na capital do Amazonas. O objetivo principal da presente pesquisa é evidenciar a importância da experiência sensorial para promover negócios de sucesso em Manaus, em que a empresa em questão, destaca-se por proporcionar aspectos do design sensorial em seu estabelecimento. Para cumprir o objetivo geral foi determinado os seguintes objetivos específicos:

- Observar o espaço comercial do supermercado com base na percepção sensorial;

- Consultar a opinião dos consumidores do supermercado sobre suas experiências com a marca;

- Verificar quais atributos do design sensorial devem se tornar necessários para gerar experiências positivas aos consumidores do supermercado estudado.

\section{Design Sensorial}

O design sensorial segundo os autores Braida e Nojima (2008), volta-se para o projeto de ambientes e objetos que despertam os sentidos, sendo compreendido de maneira holística, pois são estimulados na totalidade e não de forma individual. Ademais, o autor Lindstrom (2011) afirma ser muito limitador explorar somente um dos sentidos, pois se obtém apenas uma faceta e não uma visão do projeto por completo. Dessa forma, cria-se a necessidade de identificar maneiras de promover a experiência sensorial unificada, pois é muito comum encontrar produtos/ambientes esteticamente agradáveis, mas que não correspondem o suficiente o quesito ergonomia, isso acontece, pois, no momento de concepção teve-se o foco maior no visual, deixando de lado as necessidades do usuário. Compreende-se que o papel do design sensorial é 
propor maneiras de instigar o público através de uma experiência multissensorial, visando aprimorar a relação entre público e empresa.

\subsection{Estímulos Visuais}

A utilização do design sensorial acontece por meio dos cinco sentidos, é atribuído a cada um deles a função de captar uma categoria de estímulos. Wellert (2013) afirma que a visão tem sido o sentido com maior aproveitamento no marketing, pois a comunicação normalmente atua ao nível visual, como anúncios, outdoors, panfletos, entre inúmeros outros. Nesta circunstância, ferramentas como a teoria da cor podem ser utilizada como suporte para trabalhar a experiência visual, pois, evidencia três aspectos importantes: os físicos, fisiológicos e os culturais simbólicos, e que precisamente, pode-se direcionar para interação com o ser humano, através da psicologia das cores, que utiliza a coloração estrategicamente para transmitir uma mensagem ou sensação, além de atrair e persuadir visualmente o usuário (SILVEIRA, 2015). Além disso, existem outras alternativas como: decoração, logotipo, forma dos produtos, todos esses e outros, quando bem aplicados, permitem criar uma experiência atrativa e memorável.

\subsection{Estímulos Sonoros}

Segundo Abel e Glinert (2008), os estímulos auditivos fazem conexão direta com os circuitos emocionais do público, pois afetam a experiência e interpretação do usuário perante a marca, evocando respostas comportamentais, como aproximação, afastamento e permanência no ambiente. Este receptor pode ser explorado através de músicas, melodias, sons, jingles, visando aprimorar a experiência do usuário. Os estímulos sonoros quando bem aplicados podem influenciar no comportamento e hábitos de compra, assim como ser um forte aliado para proporcionar memórias afetivas e duradouras nos clientes. Desse modo, quando é feita uma seleção de músicas e sons pensando no público-alvo que frequenta o estabelecimento, os consumidores podem ter a sensação de que passaram menos tempo fazendo compras do que realmente passaram, obtendo assim uma experiência agradável e pode ser tomada como critério para um possível retorno.

\subsection{Estímulos Táteis}

Os autores, Peck e Childers (2003), afirmam que o tato é um dos sentidos mais íntimos, pois envolve o contato físico com a pele, mediante o toque pode-se sentir a textura, qualidade, temperatura, conforto e a consistência dos produtos e ambientes. $\mathrm{O}$ tato pode proporcionar familiaridade com o espaço de uma empresa, pois permite o público fortalecer as experiências quando os outros sentidos não podem ser totalmente utilizados, ocasiona-se o aumento de compras espontâneas, devido ao fácil acesso das mercadorias de forma atrativa para o consumidor. Em vista ao desejo do público em interagir com produtos e ambientes voluntariamente, torna-se necessário proporcionar essa experiência acessível e ergonômica, visando envolver ainda mais o consumidor por meio do bem-estar.

\subsection{Estímulos Gustativos}

O paladar possui correlação ao olfato, ambos se encontram quimicamente ligados. Entretanto, para Lindstrom (2011) é praticamente impossível estimular o paladar sem o aroma, no entanto, é executável tirar vantagem do aroma sem incluir a degustação. O paladar é o sentido menos explorado, devido à diversidade de preferências do público, bem como a dificuldade de utilizar em panoramas que não estejam integrados no ramo alimentar. Contudo, o autor Gobé (2011) afirma que uma alternativa para oferecer estímulos ao paladar são as ofertas de bebidas ou alimentos de maneira a recepcionar o público que frequenta o ambiente comercial. Estas práticas podem implementar os valores da marca, ocasionando uma experiência sensorial satisfatória, marcante e menos estressante para o consumidor, de maneira a os instigar a permanecer mais tempo na loja, ocasionando assim níveis superiores de consumo. 


\subsection{Estímulos Olfativos}

Utilizar aromas estrategicamente em um ambiente ou produto é uma alternativa utilizada pelo design sensorial de modo a oferecer uma forte ligação das emoções e memórias do consumidor com a marca. Este receptor pode ser explorado através de fragrâncias aplicadas ao ambiente e/ou aos produtos, estimulando sensações positivas no público e relacionando-se ao bem-estar. Segundo Tomazelli e Espartel (2010), a combinação do aroma com o espaço comercial, tende a criar vínculos afetivos com o público quando utilizado de maneira sutil, desencadeando recordações ao sentir determinado cheiro e associar a marca ou produto.

\subsection{Práticas Sensoriais}

Segundo Lindstrom (2011), os apelos sensoriais tendem a despertar sensações/emoções e a permanecer por mais tempo na mente do consumidor. Nesse sentido, quanto mais recordações afetivas, maior será o vínculo entre a marca e o consumidor, para isso, reforça-se a necessidade de integrar os sentidos a partir das técnicas do design sensorial. Entretanto, para Haverkamp (2012), existe uma limitação metodológica, considerando a quantidade de estudos voltados para percepção visual serem incontáveis, dificulta-se explorar formas de promover a integração dos sentidos e aplicá-las na experiência do usuário. Portanto, estas práticas não devem limitar-se exclusivamente ao visual, deve-se estimular o consumidor de maneira que desperte sua percepção e a memória afetiva, utilizando outros sentidos ao seu dispor. Assim surge o questionamento de como o design sensorial pode oferecer uma experiência positiva no consumidor e qual sua importância ao proporcionar novas estratégias comerciais.

\section{Objeto de estudo}

O supermercado analisado, inaugurado em 2015 na cidade de Manaus, estado do Amazonas, passou a se destacar por proporcionar experiências com foco multissensorial, distinguindo-se de outros supermercados da localidade. Baseado no sucesso do primeiro estabelecimento, nasceu em 2019 uma nova unidade, no entanto, com algumas implementações estéticas diferenciadas do primeiro estabelecimento e um restaurante maior em comparação ao primeiro, contendo conceitos da alta gastronomia internacional.

O supermercado estudado é uma empresa exemplo quanto a oferta de experiências sensoriais para o usuário, isso se deve pelo uso do conceito 'Mercado terapia', em que se pretende criar uma extensão de casa no ambiente visitado, por meio do relaxamento, comodidade e praticidade para seus clientes. Suas lojas oferecem serviços diferenciados de compra, como atendimento self checkout (máquina que funciona como caixa que o próprio cliente registra e paga suas compras) e o de e-commerce (comércio virtual), restaurante, aliado a venda de produtos com marcas importadas, destacando a atuação forte na linha de alimentos saudáveis e orgânicos.

O proprietário, baseado em sua experiência anterior como superintendente de outra rede de supermercado, compreendeu as dores do público e o que os instiga a comprar um produto, dessa forma propôs oferecer uma vivência diferenciada dos demais estabelecimentos. O proprietário investiu em seu projeto uma estrutura e decoração a qual busca transformar uma atividade monótona como fazer compras no mercado, em uma experiência agradável para o consumidor, através de decisões estéticas que estimulam o público, não só visualmente, mas utilizando os demais sentidos que passam despercebidos por outras empresas do segmento.

Desse modo, criou-se a importância de elaborar a presente pesquisa, através do estudo de caso sobre o supermercado em questão, considera-se que os resultados alcançados, poderão fornecer uma contribuição significativa para o conhecimento sobre o papel do design sensorial em supermercados, bem como, pontuar 
sua importância na busca de criar conexões entre o consumidor e marca. A decisão de centrar esta pesquisa em um supermercado é justificada pelo fato de se tratar de um estabelecimento que possui o contato com inúmeros consumidores a todo momento, podendo dessa maneira oferecer o desenvolvimento de diversas experiências ao usuário. Em contrapartida, a ampla concorrência nesta categoria comercial, impõe-se a necessidade de pesquisar sobre métodos e ferramentas que auxiliem a oferta de experiências diversificadas para o público. Portanto, o design sensorial destaca-se como uma ferramenta fundamental, para empresas que procuram proporcionar vivências diferenciadas, visto que o fator decisivo para os consumidores é a experiência (SCHMITT, 1999).

\section{Procedimentos Metodológicos}

A pesquisa é de caráter descritivo e exploratório utilizando técnicas qualitativas e quantitativas baseadas em pesquisa bibliográfica e documental (GIL, 2008). Em vista disso e dos objetivos estabelecidos, foi selecionado para a investigação, de forma intencional, um estudo de caso, em que o autor Fonseca (2002) conceitua como uma pesquisa que visa conhecer em profundidade as vertentes do objeto de estudo, possibilitando compreender e identificar aspectos, características que há de mais essencial ou problemático em determinada situação.

O estudo de caso, teve como complemento a pesquisa de campo, em que Gil (2008) conceitua como uma investigação que visa utilizar mais técnicas de observação do que de interrogação. A fase de desenvolvimento desse estudo contemplou o período de oito meses, considerando o tempo para pesquisa de campo, aplicação do questionário juntamente análise desses dados e a realização da técnica focus group. A amostra das informações coletadas foi composta por 40 entrevistados, sendo 32 respondentes do questionário e 8 participantes do focus group (4 professores e 4 bolsistas de iniciação científica), a maioria residente e pertencente à cidade de Manaus.

\subsection{Etapas da Pesquisa em Design}

Os métodos projetuais utilizados para essa pesquisa foram: Systematic Methods for Designers, criado por Bruce Archer, em 1965, que trata da organização do processo criativo e (de modo mais formal) torna possível alcançar resultados mais científicos; e o Modelo de Design Concorrente desenvolvido por Hernandis, em 2003, que observa os atributos do design tanto em produtos como em serviços oferecidos por empresas e mercado de atuação nos mais variados ramos.

Ao iniciar pelo estudo de Archer, observou-se que o seu modelo de processo se encontra resumido em três grandes fases: (1) Preliminar, aborda a etapa inicial da pesquisa em que se define os objetivos e restrições do projeto, como o referencial teórico, tem-se a definição do problema e antecede coleta de dados. Esse processo é baseado no raciocínio intuitivo, de modo que não se imponha limites no processo criativo. (2) A fase analítica é composta pela análise das informações coletadas, síntese desses resultados e, cria-se a geração de alternativas e a seleção delas para se chegar a uma solução, utilizando o raciocínio dedutivo e tomada de decisões. (3) E por fim, a fase executiva que aborda sobre as conclusões do trabalho juntamente as sugestões. Para essa pesquisa, foram utilizadas de maneira sequencial (Figura 1): pesquisa bibliográfica, pesquisa de campo, consulta com o público, discussão em grupo e sugestões de melhorias. 

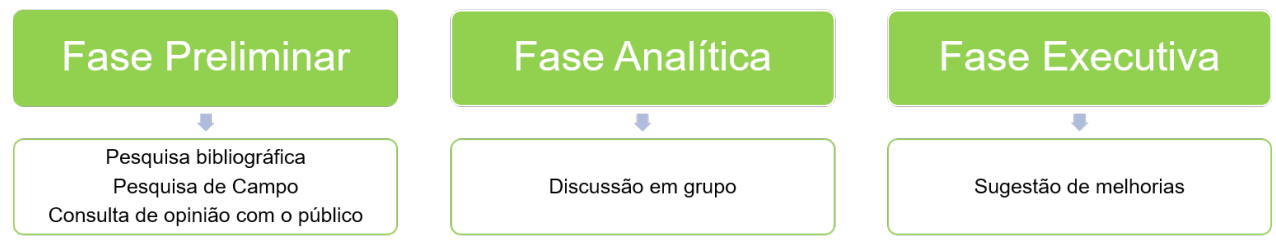

Figura 1. Etapas da pesquisa nos moldes do processo desenvolvido por Bruce Archer

Fonte: Autoras (2020)

Sobre o Modelo de Design Concorrente (Hernandis, 2003), o trabalho tomou por base as orientações referentes à identificação e observação das variáveis essenciais para o design, sendo ele voltado para produtos, serviços e/ou processos, conforme os seguintes atributos projetuais: formal, funcional e ergonômico. Além disso, a estrutura oferecida pelo modelo sistêmico (Figura 2), proporciona uma boa visibilidade aos projetos voltados ao design sensorial, o que permite um melhor diagnóstico dos fatores relacionados à competitividade do objeto de estudo para o seu desempenho no mercado e, ainda, um diagnóstico preliminar quanto à experiência do usuário e o ambiente oferecido pelo estabelecimento.

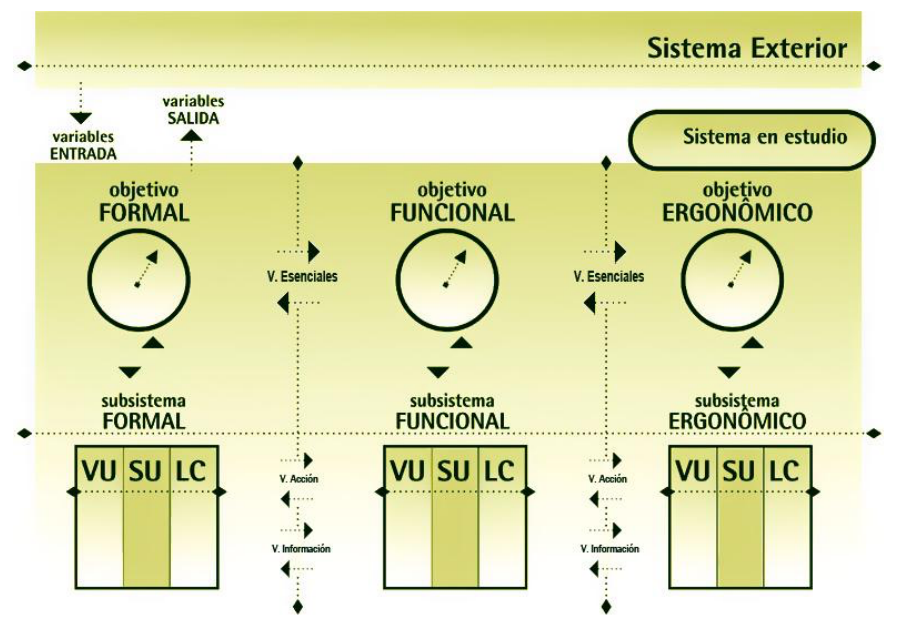

Figura 2. Modelo de design concorrente Fonte: (Hernandis, 2003).

\subsubsection{Pesquisa bibliográfica}

A pesquisa foi estruturada com base na sistematização de informações obtidas através de registros bibliográficos e documentais sobre: design sensorial; experiência do usuário; estudo de caso; elaboração e aplicação de questionário junto ao consumidor; prática de técnicas como focus group; e a análise de dados qualitativos e quantitativos. A partir de cada referência consultada, o trabalho avançou com as etapas estabelecidas para a obtenção dos objetivos traçados pelo estudo. Além disso, essa organização realizada para cada assunto, possibilitou registrar e ordenar as informações de modo exploratório e descritivo, proporcionando um conhecimento mais conceitual e aplicado sobre o tema proposto, auxiliando também de forma estratégica sobre como identificar os atributos do design necessários para a melhoria dos aspectos falhos observados no objeto de estudo.

\subsubsection{Pesquisa de campo}

Tomando como objeto de estudo uma das unidades de uma grande empresa de supermercados atuante na cidade de Manaus, a pesquisa de campo foi realizada com base nas informações bibliográficas coletadas e nos modelos projetuais de design. Todos os dados foram conduzidos mediante as problemáticas identificadas no estabelecimento analisado. Após uma melhor organização dos elementos observados que condizem com 
os aspectos conceituais e práticos da percepção sensorial, apresentada diante o espaço comercial do supermercado, foi possível fazer uma avaliação através das orientações de Prodanov e Freitas (2013), a respeito dos seus pontos fortes e fracos do local, cumprindo o primeiro objetivo específico do estudo.

\subsubsection{Consulta de Opinião}

Os dados, foram coletados a partir da aplicação de um questionário, construído em blocos temáticos obedecendo a uma ordem lógica para a sua elaboração, cujo roteiro contém perguntas abertas (respostas livres), fechadas (duas opções), e de múltipla escolha (fechada com uma série de respostas possíveis), apresentando um total de 16 questões. Essa etapa está relacionada ao segundo objetivo específico desta pesquisa, em que se buscava consultar a opinião dos consumidores do supermercado sobre suas experiências com a marca.

A seleção dos entrevistados foi aleatória, buscando cobrir os potenciais consumidores em termos dos produtos e serviços oferecidos pelo objeto de estudo, assim a aplicação do questionário foi realizada via internet em um período de 10 dias e teve como princípio técnico o uso do conceito "bola de neve" evidenciado por Bailey (1992), o que proporcionou uma interação efetiva entre os informantes e a pesquisa. A síntese dos resultados obtidos foi quantitativa, a qual foi mensurado o reconhecimento do público-alvo, a compreensão dos respondentes sobre as experiências relacionadas a proposta sensorial oferecida pelo supermercado estudado. Desse modo, identificaram-se os pontos positivos e negativos do objeto de estudo em relação à utilização do design sensorial, do ponto de vista dos consumidores.

\subsubsection{Discussão em grupo}

Essa etapa está interligada ao terceiro objetivo específico da presente pesquisa, a qual apontou-se verificar quais atributos do design sensorial devem se tornar necessários para gerar experiências positivas aos consumidores do supermercado estudado. Com base na síntese dos resultados do questionário com o público e referências do modelo sistêmico de Hernandis (2003), desenvolveu-se conteúdo para aplicação da técnica focus group, centrada nos aspectos sensoriais e funcionais oferecidos pela empresa, portanto, foi observado o diálogo entre os participantes, composto por professores doutores em Design e Gestão estratégica de projetos e bolsistas de iniciação científica e tecnológica em Design (ICT). As questões utilizadas para interação dos respondentes eram de múltipla escolha, oferecendo também a oportunidade para os integrantes expressarem suas opiniões sobre cada tópico abordado, com isso, obteve-se a geração de ideias e a contribuição espontânea dos membros na reunião.

\subsubsection{Sugestões}

Através da execução dos objetivos estabelecidos para a presente pesquisa e com análise e síntese das informações coletadas, pontuaram-se sugestões ao ambiente estudado, com foco sobre a experiência sensorial oferecida para o consumidor, visando contribuir para o campo científico, apontando a importância do design sensorial na busca de criar conexões afetivas entre o público e marca.

\section{Resultados}

\subsection{Observação com base na percepção sensorial}

Por meio da pesquisa de campo, foi realizada uma análise detalhada sobre aplicação do design sensorial no ambiente do supermercado, localizado em Manaus, capital do Amazonas, observando suas decisões estéticas, funcionais e ergonômicas. 


\subsubsection{Visão}

Segundo Cauduro e Martino (2005), a marca é um signo criado para fortalecer a identidade visual de uma empresa e promovê-la dentro de um contexto social, qualificando assim suas relações humanas internas e externas. O supermercado estudado visa promover a saúde e bem-estar, e associa esses conceitos a sua imagem, através da decoração no ambiente e por seu logotipo, que utiliza as cores cinza-escuro, branco e verde. As duas primeiras cores remetem elegância e modernidade, enquanto o verde corresponde ao frescor, à natureza e à vitalidade (HELLER, 2013). Estas alegações são baseadas na psicologia das cores, juntamente os conhecimentos da teoria da cor, pois a coloração pode cativar visual e emocionalmente o consumidor, segundo a campanha mercadológica proposta.

O supermercado aproveita os cinco sentidos, para representar seus valores ao público. O design do espaço é organizado de modo que, o posicionamento das mercadorias, juntamente a iluminação utilizada, seja de extrema relevância, causando atração e destaque para quem observa, bem como o uso de prateleiras de madeira que além de realçar os produtos, trabalham o conceito de ambiente elegante e orgânico.

\subsubsection{Olfato}

Estimular o olfato pode trazer familiaridade do consumidor com o local visitado, pois afeta diretamente suas memórias. Os autores Acevedo e Fairbanks (2018) afirmam:

Os aromas têm a capacidade de influenciar o estado de espírito das pessoas, e isto ocorre porque o cheiro estimula o sistema límbico, que é a parte do cérebro responsável pelas respostas emocionais. Assim, o olfato é um sentido químico com ligação "direta" a uma zona do cérebro responsável pelo processamento das emoções (a amígdala) e das memórias, o hipocampo (ACEVEDO e FAIRBANKS, 2018).

Devido à logística exercida no supermercado, os produtos orgânicos são trocados diariamente, para preservar a aparência e o aroma fresco. Então o consumidor quando exposto a uma fragrância agradável, inconscientemente o associa ao ambiente. Dessa maneira, a empresa ganha destaque ao utilizar aromas marcantes no local de trabalho.

\subsubsection{Audição}

Segundo Lindstrom (2011), a música pode desenvolver estímulos diretos ao humor, criando sentimentos e emoções no sistema cognitivo do cliente. Fazer as compras pode ser uma atividade demorada e estressante, uma seleção musical adequada, pode ser eficaz para tornar a experiência relaxante para o consumidor, pois fortalece o vínculo e a memória afetiva entre o cliente e a marca.

O supermercado observado opta por utilizar músicas calmas e relaxantes, como também em determinadas ocasiões proporciona ao público apresentações de músicos no estabelecimento, centrado em oferecer uma experiência diversificada aos frequentadores do estabelecimento.

\subsubsection{Tato}

O tato é um grande auxiliador na hora das compras, principalmente para analisar a qualidade dos produtos e observar também aspectos ergonômicos. Schiffman (2005) aponta a pele como responsável pela percepção de objetos, superfícies e pela manifestação de sensações térmicas e dolorosas. A unidade do supermercado consultada proporciona em seu estabelecimento uma extensão de casa, a mobília transmite comodidade, conforto e o espaço permite a livre circulação do público e os colaboradores, na entrada do local fica a disposição um pote com mensagens positivas, buscando oferecer laços afetivos com seus clientes. 


\subsubsection{Paladar}

Segundo Schiffman (2005), a boca percebe informações associadas ao tato, como localização relativa, volume, textura e temperatura das substâncias. Dessa forma, o paladar assim como o tato é relacionado às experiências do usuário, no entanto, é necessária uma interação mais direta dos outros quatro sentidos para se obter melhores resultados. Nesse contexto, o estabelecimento disponibiliza aos frequentadores, em especial o público infantil amostras grátis de frutas frescas no hall de entrada, para estimular a saúde e bem-estar, correspondendo aos objetivos defendidos pela empresa.

\subsection{Análise sobre as experiências do público-alvo com os serviços do supermercado}

Os destaques e limitações da experiência sensorial oferecida no supermercado, foram identificados através da consulta de opinião com o público-alvo sobre as experiências obtidas com os produtos e serviços da empresa, para isso foi elaborado um questionário online, por meio do Google Forms, disponibilizado via redes sociais aos respondentes em um período de 10 dias, com 16 perguntas distribuídas em 4 seções: sobre você, experiência do usuário e experiência sensorial, bem como um setor destinado a quem relatou não conhecer o estabelecimento, desse modo foi direcionado ao fim do questionário, por não se caracterizar como grupo-alvo. Este instrumento foi utilizado, pois apresenta as mesmas questões a todos os inquiridos, garante $\mathrm{o}$ anonimato e contém perguntas que atendem às mesmas finalidades específicas da pesquisa. De acordo com Coutinho (2011), os questionários assemelham-se às entrevistas, mas dispensam a presença do entrevistador. Nesse sentido, são aplicados a diferentes situações, permitindo maior exatidão com os dados coletados e atingindo um vasto número de pessoas.

\subsubsection{Primeira seção do questionário (Sobre você)}

Ao fim do prazo para coleta das respostas dos usuários, foram obtidas trinta e duas respostas, nos quais vinte e duas foram válidas para este estudo, pois se referem às pessoas que já tiveram alguma experiência com a empresa estudada, o restante dos participantes foram dispensados por não apresentar o perfil de público-alvo do supermercado. A primeira seção de perguntas estava destinada a identificar o perfil desse grupo de pessoas que conhecem ou já frequentaram o estabelecimento, esses dados mostram que o público consultado é majoritariamente feminino (56,3\%), com a faixa etária entre 17- 20 anos $(61,5 \%)$, estado civil solteiro $(84,6 \%)$. Em resumo dessa primeira seleção de dados coletados no questionário online, foi possível delinear o perfil do grupo-alvo. Ilustrado conforme a figura 3.

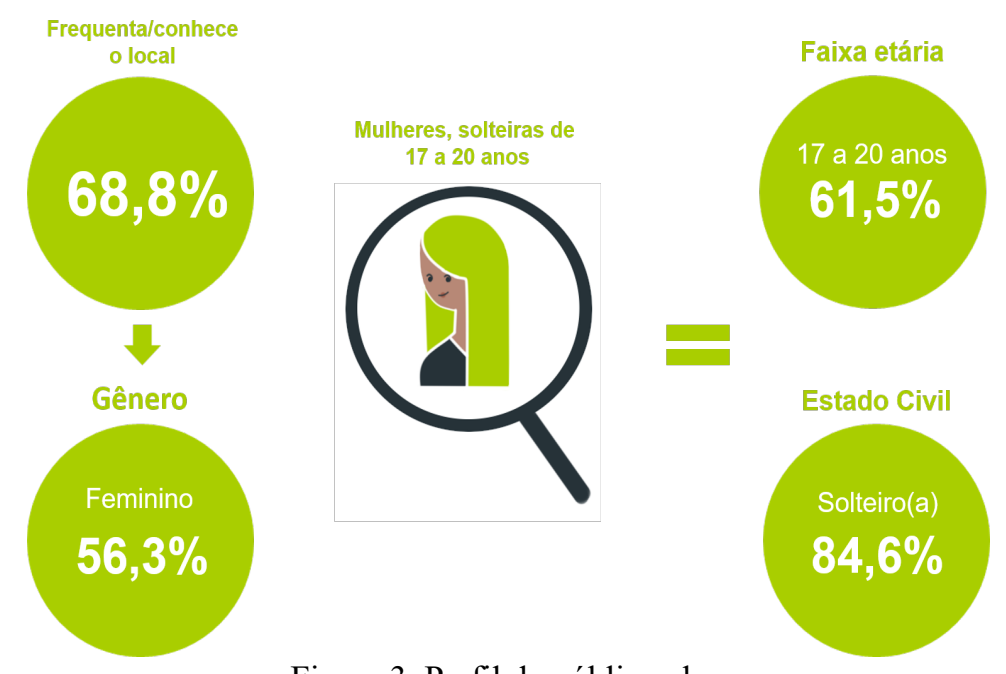

Figura 3. Perfil do público alvo

Fonte: Autoras (2020) 


\subsubsection{Segunda seção do questionário (Experiência do usuário)}

Através da segunda seção do questionário foi obtido dados quanto à vivência dos clientes, identificando a opinião do público sobre o ambiente, produtos e serviços do supermercado conforme a experiência ao visitar o local. Por meio das respostas destaca-se que a unidade mais frequentada é localizada na Avenida Djalma Batista, zona centro-sul de Manaus. É importante salientar que as próximas perguntas desta seção foram de múltipla escolha (Tabela 1), nesse sentido, nota-se os motivos que levam o público consultado a frequentar o supermercado é a exclusividade nos produtos oferecidos e o ambiente ser calmo e agradável, ambos com $68,2 \%$ dos votos. Análise dos respondentes sobre o ambiente destaca que o local é moderno (90,9\%), bem organizado e limpo/higiênico, cada um com $86,4 \%$ dos votos.

\begin{tabular}{|c|c|c|c|}
\hline $\begin{array}{c}\text { Motivos pelos quais o público frequenta } \\
\text { o Supermercado }\end{array}$ & $\begin{array}{c}\text { Percentual dos votos } \\
\text { obtidos }\end{array}$ & $\begin{array}{c}\text { Análise do público sobre o } \\
\text { ambiente visitado }\end{array}$ & $\begin{array}{c}\text { Percentual dos } \\
\text { votos obtidos }\end{array}$ \\
\hline Qualidade dos itens da padaria & $4,5 \%$ & Bem organizado & $86,4 \%$ \\
\hline Variedade de serviços & $54,5 \%$ & Moderno & $90,9 \%$ \\
\hline O preço dos produtos & $0 \%$ & Limpo/Higiênico & $72,7 \%$ \\
\hline Exclusividade nos produtos & $68,2 \%$ & Funcional & $86,4 \%$ \\
\hline Local de fácil acesso & $27,3 \%$ & Seguro & $77,3 \%$ \\
\hline O local atrai esteticamente & $50 \%$ & Tranquilo & $59,1 \%$ \\
\hline O ambiente é calmo e agradável & $68,2 \%$ & & $72,7 \%$ \\
\hline
\end{tabular}

Tabela 1. Avaliação dos respondentes sobre a experiência com o supermercado Fonte: Autoras (2020)

Identificou-se o nível de satisfação dos usuários sobre os serviços oferecidos pelo supermercado em uma escala de um a cinco, a nota que recebeu mais votos foi a número cinco, obtido através de $13(59,1 \%)$ dentre as 22 respostas adquiridas. Ao fim da segunda seção de perguntas sobre a experiência do usuário, determinou-se a visão do público de maneira geral sobre o supermercado estudado (Gráfico 1), as respostas contidas nessa pergunta eram de múltipla escolha, evidenciou-se que a empresa dispõe qualidade em seus serviços (20 votos ao total) e estimula o desejo de compra nos frequentadores (22 votos ao total).

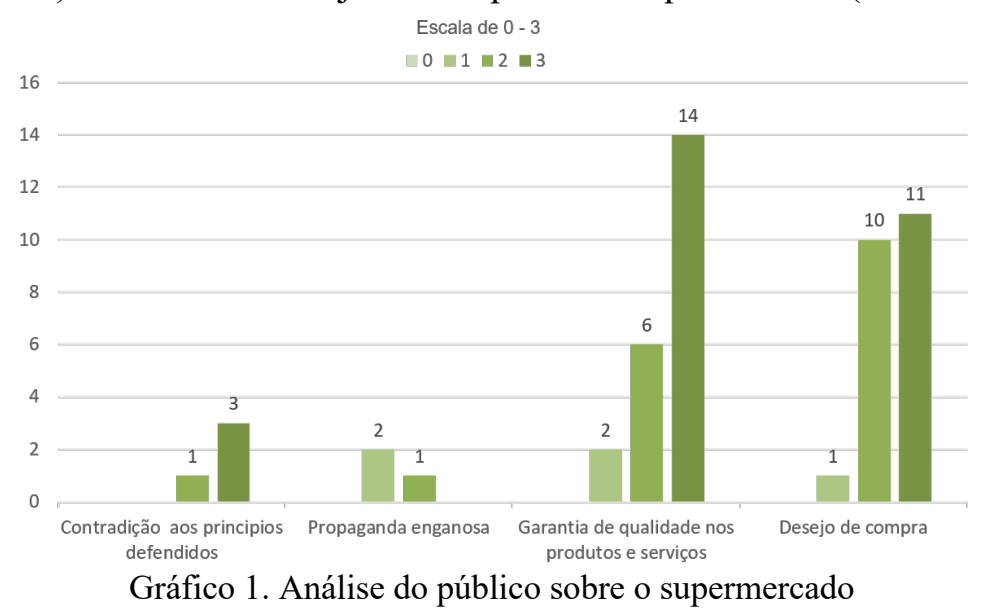

Fonte: Autoras (2020) 


\subsubsection{Terceira seção do questionário (Experiência Sensorial)}

A terceira seção de perguntas identificou a percepção do público sobre aspectos de design sensorial utilizados no ambiente do supermercado e obteve feedback mediano, pois com 63,6\% salientou-se que a empresa se diferencia no mercado ao proporcionar experiências multissensoriais aos usuários, de modo que transmita sentimentos positivos $(45,5 \%)$ no consumidor, no entretanto, ainda que o estabelecimento tenha um retorno efetivo sobre a percepção do público em relação aspectos de design sensorial no local, este aspecto não tem sido motivo suficiente para os respondentes denotarem o supermercado como preferência para fazer compras (Figura 4).

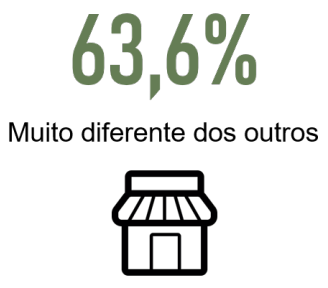

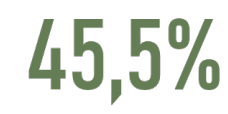

Sentimentos positivos

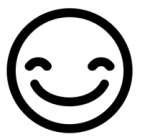

Figura 4. Valor da marca

Fonte: Autoras (2020)

O gráfico 2 abaixo apresenta um comparativo entre o que influencia o público na aquisição de um produto e quais sentidos são mais estimulados durante as compras no local. Os sentidos: visão, audição, olfato e o tato foram apontados como os que mais interferem na decisão da compra, assim como são os mais perceptíveis no ambiente do supermercado apenas descartando o tato, pois este é indicado como um dos menos trabalhados no local acompanhado ao paladar.

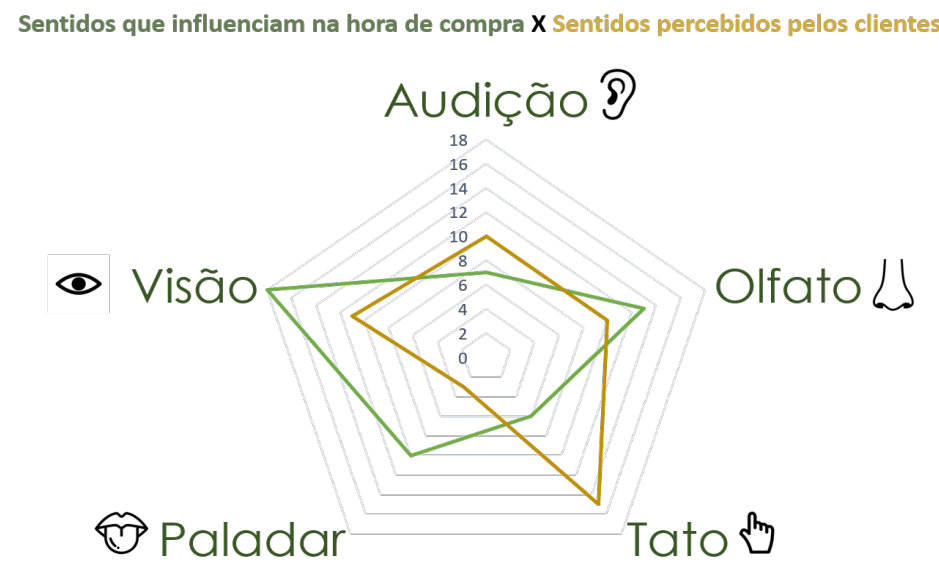

Gráfico 2. Análise dos estímulos sensoriais no ato de compra Fonte: Autoras (2020)

\subsection{O Design Sensorial para uma experiência positiva nos consumidores}

Para a obtenção dos resultados referentes aos atributos de design sensorial que devem ser considerados necessários para dispor experiências positivas aos consumidores do supermercado, aplicou-se o focus group com um grupo de participantes, formado por oito pessoas sendo elas: quatro professores doutores em Design e Gestão estratégica de projetos e quatro bolsistas de ICT em Design da Universidade Federal do Amazonas, 
este recurso foi realizado através de uma plataforma de videoconferência (Google Meet), devido ao isolamento ocasionado pela pandemia de COVID-19. Após uma breve apresentação sobre o objeto de estudo, foi aplicado um questionário constituído em nove perguntas de múltipla escolha, oferecendo também oportunidade de os participantes compartilharem suas opiniões, este questionário foi aplicado a partir de três blocos identificados com os atributos do design (forma, função e ergonomia), referenciados no modelo sistêmico de Hernandis (2003). Os dados coletados foram organizados em três quadros para auxiliar a análise das opiniões e apontar os resultados de acordo com cada atributo. Desse modo, é possível destacar importantes variáveis do design sensorial para contribuir no trabalho de gerar vivências positivas no supermercado. Apontam-se a seguir as análises realizadas para os atributos do design estratégico: FORMA, FUNÇÃO e ERGONOMIA, coletados a partir do público consultado.

\begin{tabular}{|c|c|c|c|c|c|c|c|c|c|c|}
\hline \multirow{2}{*}{\multicolumn{2}{|c|}{$\begin{array}{l}\text { Design Sensorial } \\
\text { FORMA }\end{array}$}} & \multicolumn{4}{|c|}{$\begin{array}{l}\text { Doutores em Design e Gestão } \\
\text { Estratégica de Projetos }\end{array}$} & \multicolumn{4}{|c|}{ Bolsistas de ICT em Design } & \multirow{2}{*}{$\begin{array}{c}\text { Resultados } \\
\text { Opiniões } \\
\text { Estratégias }\end{array}$} \\
\hline & & $\begin{array}{c}\text { Doutor } \\
1\end{array}$ & $\begin{array}{l}\text { Doutor } \\
2\end{array}$ & $\begin{array}{l}\text { Doutor } \\
3\end{array}$ & $\begin{array}{c}\text { Doutor } \\
4\end{array}$ & $\begin{array}{c}\text { Aluno } \\
1\end{array}$ & $\begin{array}{l}\text { Aluno } \\
2\end{array}$ & $\begin{array}{c}\text { Aluno } \\
3\end{array}$ & $\begin{array}{l}\text { Aluno } \\
4\end{array}$ & \\
\hline \multirow{3}{*}{$\begin{array}{c}\text { Marca/Layout } \\
\text { Supermercado: } \\
\text { Redesign? }\end{array}$} & $\operatorname{Sim}$ & $\checkmark$ & & & & & & & & \\
\hline & Talvez & & $\checkmark$ & & & $\checkmark$ & $\checkmark$ & $\checkmark$ & & $\checkmark$ \\
\hline & Não & & & $\checkmark$ & $\checkmark$ & & & & $\checkmark$ & \\
\hline \multirow{3}{*}{$\begin{array}{l}\text { Produto/Serviço } \\
\text { Refletem a Marca }\end{array}$} & Sim & & $\checkmark$ & $\checkmark$ & $\checkmark$ & $\checkmark$ & $\checkmark$ & & $\checkmark$ & $\checkmark$ \\
\hline & Talvez & $\checkmark$ & & & & & & $\checkmark$ & & \\
\hline & Não & & & & & & & & & \\
\hline \multirow{3}{*}{$\begin{array}{l}\text { Mercado terapia } \\
\text { Fator Estético }\end{array}$} & Sim & & $\checkmark$ & $\checkmark$ & & $\checkmark$ & $\checkmark$ & $\checkmark$ & & $\checkmark$ \\
\hline & Talvez & $\checkmark$ & & & $\checkmark$ & & & & $\checkmark$ & \\
\hline & Não & & & & & & & & & \\
\hline
\end{tabular}

Tabela 2. Respostas referente ao atributo Forma - Focus Group. Fonte: Autoras (2021)

Conforme os questionamentos feitos aos participantes do focus group sobre o atributo: FORMA, os fatores estéticos (tabela 2) 'layout' do ambiente e a 'Marca' podem ter alternativas que deem mais destaque a empresa, pois mesmo oferecendo uma decoração pensada nos ideais defendidos, alguns aspectos ainda conseguem ser encontrados na concorrência, desse modo, podem ser melhorados para se obter uma identidade mais exclusiva. Dos oito participantes, seis concordam que os produtos/serviços oferecidos reforçam os valores da marca. Quanto à ideia de 'Mercado terapia', o estabelecimento busca oferecer aos seus clientes sensação de comodidade, praticidade e extensão de casa no ambiente visitado por meio dos móveis e decoração, dois doutores e três bolsistas foram favoráveis ao fator estético utilizado, desse modo concordam com as decisões tomadas sobre ergonomia e decoração no ambiente. 


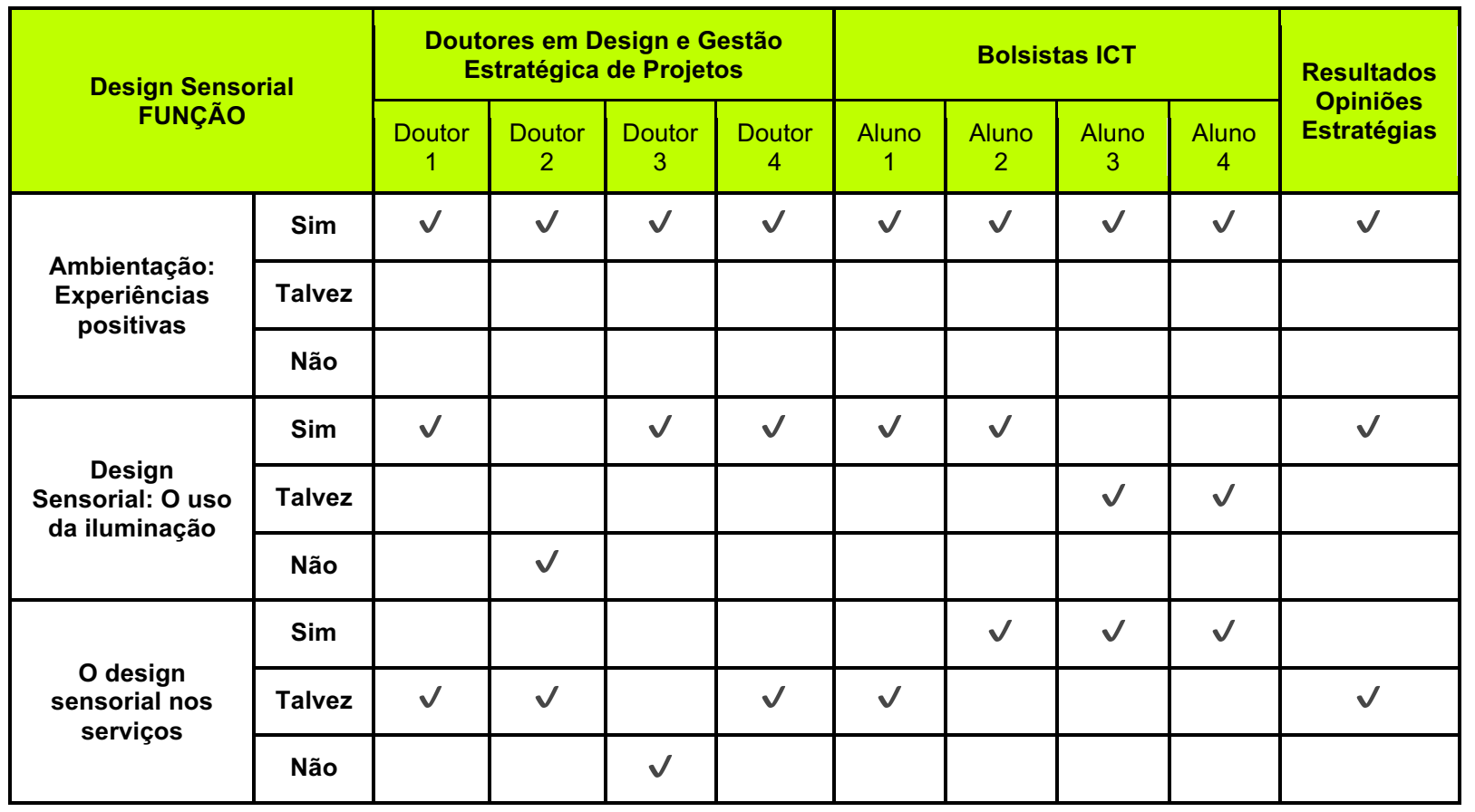

Tabela 3. Respostas referente ao atributo Função - Focus Group.

Fonte: Autoras (2021)

O segundo bloco é atribuído o aspecto: FUNÇÃO (tabela 3), quando consultados sobre os estímulos sensoriais no ambiente, a audição obteve aprovação por parte dos oito participantes, confirmando que o uso de sons no local, através de playlists de músicas ambientes e música ao vivo, resultam em uma experiência positiva para o usuário. Com relação à estimulação da visão, aplicação da iluminação atua como um dos aspectos visuais mais explorados no espaço do supermercado, e obteve uma resposta otimista por parte de três doutores e dois bolsistas de ICT, evidenciou-se a importância do emprego de diferentes tons de iluminação conforme as seções, onde se tem o propósito de atrair a atenção do consumidor. Os demais sentidos como: tato, paladar e olfato são instigados através da decoração, mobília, oferta de frutas frescas destinado às crianças e aos aromas utilizados em cada seção do supermercado. Há uma concordância por parte dos integrantes (três doutores e um bolsistas de ICT), estes apontam ser viável a busca de mais alternativas para explorar os três sentidos que passam despercebidos, com o intuito de aprimorar sensorialmente a interação dos clientes com o ambiente.

\begin{tabular}{|c|c|c|c|c|c|c|c|c|c|c|}
\hline \multirow{2}{*}{\multicolumn{2}{|c|}{$\begin{array}{l}\text { Design Sensorial } \\
\text { FORMA }\end{array}$}} & \multicolumn{4}{|c|}{$\begin{array}{l}\text { Doutores em Design e Gestão } \\
\text { Estratégica de Projetos }\end{array}$} & \multicolumn{4}{|c|}{ Bolsistas ICT em Design } & \multirow{3}{*}{$\begin{array}{c}\text { Resultados } \\
\text { Opiniões } \\
\text { Estratégias }\end{array}$} \\
\hline & & \multirow{2}{*}{$\begin{array}{l}\text { Doutor } \\
1\end{array}$} & \multirow{2}{*}{$\begin{array}{l}\text { Doutor } \\
2\end{array}$} & \multirow{2}{*}{$\begin{array}{l}\text { Doutor } \\
3\end{array}$} & \multirow{2}{*}{$\begin{array}{l}\text { Doutor } \\
4\end{array}$} & \multirow{2}{*}{$\begin{array}{c}\begin{array}{c}\text { Aluno } \\
1\end{array} \\
\qquad \sqrt{ }\end{array}$} & \multirow{2}{*}{$\begin{array}{c}\begin{array}{c}\text { Aluno } \\
2\end{array} \\
\qquad \sqrt{ }\end{array}$} & \multirow{2}{*}{$\begin{array}{c}\text { Aluno } \\
3 \\
\qquad \sqrt{ }\end{array}$} & \multirow{2}{*}{$\begin{array}{c}\begin{array}{c}\text { Aluno } \\
4\end{array} \\
\qquad \sqrt{ }\end{array}$} & \\
\hline \multirow{3}{*}{$\begin{array}{l}\text { Sinalização: } \\
\text { pregnante? }\end{array}$} & Sim & & & & & & & & & \\
\hline & Talvez & $\checkmark$ & & & & & & & & \\
\hline & Não & & $\checkmark$ & $\checkmark$ & $\checkmark$ & & & & & \\
\hline \multirow{2}{*}{$\begin{array}{l}\text { A largura dos } \\
\text { corredores é } \\
\text { satisfatória? }\end{array}$} & Sim & & & & & & & & & \\
\hline & Talvez & $\sqrt{ }$ & & & $\sqrt{ }$ & & $\sqrt{ }$ & & & \\
\hline
\end{tabular}




\begin{tabular}{|c|c|c|c|c|c|c|c|c|c|c|}
\hline & Não & & $\checkmark$ & $\checkmark$ & & $\checkmark$ & & $\checkmark$ & $\checkmark$ & $\checkmark$ \\
\hline $\begin{array}{c}\text { Mercado } \\
\text { terapia é } \\
\text { característica } \\
\text { do } \\
\begin{array}{c}\text { Supermercado } \\
\text { em questão }\end{array}\end{array}$ & Sim & $\checkmark$ & $\checkmark$ & $\checkmark$ & $\checkmark$ & $\checkmark$ & $\checkmark$ & $\checkmark$ & $\checkmark$ & $\checkmark$ \\
\hline & Talvez & & & & & & & & & \\
\hline
\end{tabular}

Tabela 4. Respostas referente ao atributo Ergonomia - Focus Group Fonte: Autoras (2021)

A parte final do questionário é caracterizada pelo atributo: ERGONOMIA (tabela 4), sendo este determinado pela relação entre usuário e empresa. Para os quatro bolsistas de ICT, a sinalização (placas de identificação das seções e produtos no ambiente do supermercado) é satisfatória e pregnante, porém do ponto de vista dos professores este aspecto não é o suficiente, ressalta ser possível o usuário ter dificuldades de localizar-se no estabelecimento, propõem-se melhorias nas suas disposições. Sendo o restaurante um dos serviços ofertados, há uma concordância por parte de cinco participantes (dois doutores e três bolsistas de ICT) quanto a necessidade de um reaproveitamento do espaço do restaurante de umas das unidades do supermercado, pois provoca um desconforto, tanto visual quanto ergonômico, dificultando a circulação das pessoas no local. Dentre todos os métodos utilizados pela empresa para criar interação com o consumidor, é de consenso de todos os participantes que a aplicação do 'Mercado terapia' conduz resultados favoráveis ao ambiente, pois é perceptível pelos usuários, no entanto, pode-se buscar novas alternativas de interações sensoriais para os clientes.

\section{Considerações Finais}

Diante o desafio do marketing em proporcionar estratégias inovadoras de atrair e fidelizar clientes e a postura dos consumidores cada vez mais informados e exigentes, o design sensorial surge como alternativa para tentar contornar essa problemática, de maneira a oferecer uma experiência marcante baseada na estimulação dos sentidos, destacando valores positivos atrelados ao bem-estar. Observa-se a partir do presente estudo, o design sensorial quando aplicado, resulta em experiências diferenciadas ao ambiente comercial, pois são perceptíveis para o público que frequenta o ambiente, os instigando a fazer diferenciações em relação à concorrência.

A partir de pesquisas bibliográficas, evidenciou-se como o design sensorial pode ser utilizado para promover experiências positivas em um estabelecimento. O supermercado selecionado para estudo, serviu para exemplificar a relação da experiência sensorial e a percepção do público. Foi observado o ambiente da empresa, bem como aspectos quanto à forma, função e ergonomia, identificando pontos positivos e os negativos que podem ser trabalhados para se obter uma vivência sensorial completa. O local estudado trabalha os estímulos visuais, olfativos e auditivos consideravelmente de modo que são os mais perceptíveis pelo público. É possível notar através da identidade visual utilizada no ambiente comercial, que as decisões tomadas condizem com os valores defendidos, no entanto, pode ser repensado um redesign do logotipo para torná-la ainda mais marcante. Ainda sobre os estímulos visuais, nota-se que a sinalização é outro aspecto que necessita ser trabalhado, elaborando um novo posicionamento das placas pelo estabelecimento, visando oferecer uma locomoção intuitiva para o usuário ao se situar pelo supermercado. Em relação aos estímulos olfativos, pontuam-se favoravelmente à utilização de aroma específicos em cada seção visitada, contudo não é marcante o suficiente, pode-se até ocasionar uma experiência desagradável a disposição a tantos aromas distintos, dessa forma uma alternativa seria desenvolver uma fragrância única, pretendendo fortalecer a identidade da marca e facilitar o reconhecimento a longo prazo através do cheiro. Quanto ao estímulo 
auditivo, é dispensável um feedback negativo, pois este é cumprido de maneira eficiente de modo que a música é verdadeiramente relaxante e estimulante para quem está presente no ambiente fazendo compras. Destacando os sentidos menos explorados pelo supermercado, pontua-se primeiramente o tato, pois se apresenta importante o desejo dos clientes em interagir com o ambiente, sendo assim, devem ser tomadas medidas que instiguem os clientes a se sentirem mais à vontade a relacionar- se com o supermercado. Por outro lado, o restaurante localizado em uma das unidades necessita de um replanejamento da organização de seus móveis e espaço, buscando aprimorar aspectos ergonômicos para circulação dos clientes e colaboradores. Por fim, a estimulação gustativa no ambiente do supermercado é a menos notada pelo público, pois é estimulada através de outros sentidos, como o olfato, então o local compensa esta falta por meio da oferta de amostra grátis, embora não seja aplicada constantemente, aponta-se com uma boa alternativa para suprir essa necessidade.

Por meio da pesquisa com o público que frequenta o estabelecimento, apresentou-se satisfação em frequentar o ambiente, resultado da utilização do conceito 'Mercado terapia' criado pela empresa, ocasionando experiências proveitosas e marcantes, obteve assim uma visão positiva a respeito da empresa estudada. Entretanto, apesar de as aplicações aos estímulos sensoriais serem percebidas pelo público e receber elogios, nota-se que o supermercado não é visto como preferência para a maioria dos respondentes, ainda que a aplicação do design sensorial tenha o intuito de fidelizar o público, isso se deve ao fato de que alguns de seus pontos fortes ainda podem ser encontrados em seus concorrentes que também oferecem estímulos sensoriais agradáveis aliados a serviços mais baratos. De fato, o design sensorial resulta em uma experiência satisfatória quando bem aplicado, no entanto, ressalta-se a importância de realizar uma análise de mercado para além de avaliar o que está funcionando com a concorrência, perceber de que modo é possível aprimorar os aspectos em comum para se oferecer experiências singulares. Desse modo, fica evidente que a busca em proporcionar bem-estar deve ser constante, identificando falhas que podem estar sendo responsáveis de distanciar o público do ambiente comercial, pois no fim o público escolherá a empresa pela qual mais se identifica e proporciona inovações, favorecendo uma relação afetiva e memorável.

Portanto, a importância do design sensorial como estratégia comercial é refletida por meio das oportunidades de ressaltar princípios de uma marca, ao aprimorar a experiência do usuário sensorialmente e os conduzir a desenvolver memórias afetivas e duradouras. Por fim, ao proporcionar destaque em meio a um cenário comercial competitivo e saturado, distinguindo a empresa dos demais estabelecimentos que utilizam somente tendências tradicionais, sem dar espaço para inovações.

\section{Referências Bibliográficas}

ABEL, G.; GLINERT, L. Chemotherapy as language: Sound symbolism in cancer medication names. Social Science \& Medicine, v. 66, n. 8, p. 1863-1869, 2008.

ACEVEDO, C. R.; FAIRBANKS, V. S. L. Os Efeitos do Marketing Sensorial Sobre a Experiência de Compra do Consumidor no Ponto de Venda. Revista Interdisciplinar de Marketing, v. 8, n. 1, p. 51-67, 11 dez. 2018.

ARCHER, L. B. Systematic Methods for Designers. London: Council of Industrial Design, 1965.

BAILEY, K. D. Methods of Social Research. McMillan. Nova York, EEUU, 1992.

BENITES, Tatiana. Marketing Sensorial: Como utilizar os cinco sentidos para atrair clientes. São Paulo, SP: Comunica-T, 2016. 
BRAIDA, F.; NOJIMA, V. L. Design para os sentidos e o insólito mundo da sinestesia. PUC-Rio, 2008.

CAUDURO, J. C.; MARTINO, L. Marcas CM - Cauduro Martino Arquitetos Associados. São Paulo: Imprensa Oficial, 2005.

FONSECA, J. J. S. Metodologia da pesquisa científica. Fortaleza: UEC, 2002.

GERHARDT, Tatiana E., \& SILVEIRA, Denise T. Métodos de pesquisa. Porto Alegre: Editora UFRGS, 2009.

GIL, A. C. Métodos e técnicas de pesquisa social. 6. ed. São Paulo: Atlas, 2008.

GOBÉ, M. Emotional Branding. New York: Allworth Press, 2001.

GUIMARÃES, Mayara de Sousa. Relações públicas e mídias sociais: uma análise de suas aplicações no relacionamento organizacional. 2011. 116 f. Dissertação (Mestrado em Ciências da Comunicação) Universidade Federal do Amazonas, Manaus, 2011.

HAVERKAMP, Michael. Synesthetic Design: Handbook for a multisensory approach. Walter de Gruyter, 2012.

HELLER, E. A Psicologia das cores: como as cores afetam a emoção e a razão. 1 ed. São Paulo: G. Gili, Ltda, 2013.

HERNANDIS, B. Tesis Doctoral: Desarrollo de una metodología sistémica para el diseño de productos industriales. Universidad Politécnica de Valencia, España, 2003.

LINDSTROM, M. Brandsense: segredos sensoriais por trás das coisas que compramos. Porto Alegre: Bookman, 2011.

Peck, J. e Childers, T.L. (2003). To Have and to Hold: The Influence of Haptic Information on Product Judgements. Journal of Marketing, 67(2), 35-48.

PRODANOV, C. C, FREITAS, E. C. Metodologia do trabalho científico: métodos e técnicas da pesquisa e do trabalho acadêmico. 2 ed. Novo Hamburgo: Feevale, 2013. Disponível em: $<\underline{\text { https: } / / b i t . l y / 3 v z G q 1 n}>$. Acesso em: set. 2020

RAMOS, S. Clara Pereira Coutinho. 2011. Metodologia da Investigação em Ciências Sociais e Humanas: Teoria e Prática. Interações: Sociedade e as novas modernidades, v. 11, n. 20, 30 abr. 2011.

SCHIFFMAN, Harvey Richard. Sensação e percepção. Tradução de Luís Antônio Fajardo Pontes, Stella Machado: revisão técnica Maurício Canton Bastos, Denise Rodrigues. Rio de Janeiro: LTC, 2005.

SCHMITT, B.H. Experiential Marketing: How to Get Customers to Sense, Feel, Think, Act, and Relate to Your Company and Brand. New York: The Free Press, 1999.

SILVEIRA, L. M. Introdução à teoria da cor.-2. ed. - Curitiba: Ed. UTFPR, 2015. 
TOMAZELLI, J. B; ESPARTEL, L. B.; UGALDE, M. M. Ambientação de Loja como Vantagem

Competitiva no Varejo de Confecção. Anais do IV Encontro de Marketing da ANPAD - EMA,

Florianópolis, S.C., 23-25 de maio. 2010.

TURPAULT, M., TANNEN, R. \& WELSH, B. (2013). Building stronger brands with sensory driven product design. Journal of Brand Strategy, 2(1), pp. 6-15

WELLERT, C.V. Influência dos estímulos sensoriais na experiência da marca. Dissertação (Mestrado em Gestão) - Universidade de Aveiro, Portugal, 2013.

\section{Agradecimentos}

Esta pesquisa, foi conduzida no escopo do Projeto Samsung-UFAM para Educação e Pesquisa (SUPER ${ }^{1}$ ), de acordo com o artigo 48 do decreto $n^{\circ} 6.008 / 2006$ (SUFRAMA), foi financiada pela Samsung Eletronics of Amazonia Ltda., sob os termos da lei federal $n^{\circ} 8.387 / 1991$, através do acordo 001/2020, assinado pelo Universidade Federal do Amazonas e FAEPI, Brasil.

\footnotetext{
${ }^{1}$ SUPER é um projeto da Universidade Federal do Amazonas (UFAM) em parceria com a Samsung que visa fomentar a capacitação e a pesquisa em cursos de áreas tecnológicas da UFAM. 